\title{
The intimacies of cultural studies and area studies: The case of Southeast Asia
}

\author{
Ariel Heryanto \\ The Australian National University, Australia
}

\begin{abstract}
References to area studies occasionally appear in cultural studies discourses, and vice versa, but most of them consist of terse comments made in passing. This article attempts a more substantive enquiry into a possible convergence of cultural and area studies, with specific reference to Southeast Asia. It argues that one promising scenario for studies of the region will take the form of a cultural studies, with the Inter-Asia Cultural Studies project as one model. The issue will be examined in the contexts of two related developments: the initial attempts to build locally based studies about the region, and the internationalisation of cultural studies.
\end{abstract}

\section{Keywords}

area studies, cultural studies, post-Cold War, Southeast Asia

Can cultural studies and area studies make a distinct contribution to each other? Can there be anything methodological, historical or material that will deeply connect cultural studies and Southeast Asian area studies beyond the practice of doing cultural studies on the region for a largely Anglophone audience living on the other side of the globe? This article is an attempt to re-articulate my long-standing interest in those issues (Heryanto, 2000, 2002: 21-4) by incorporating some of the more recent discussions that have not led to print or online publication. ${ }^{1}$ Instead of focusing exclusively on the intellectual aspects, it is necessary to take a broader view, including aspects such as a viable network, organised formally through an institution or otherwise. Instead of posing questions in a way that suggests that cultural studies and area studies are two separate practices, we

\footnotetext{
Corresponding author:

Ariel Heryanto, Associate Professor, School of Culture, History and Language, The Australian National University, Canberra, Australia.

Email: Ariel.Heryanto@anu.edu.au
} 
should see them as converging, and taking the shape of a Southeast Asian-focused cultural studies.

Given the wide diversity (as concept and practice) of 'cultural studies' and 'area studies', a measure of generalisation is inevitable in the brief and sketchy discussion below, but hopefully not to an intolerable extent of oversimplification or misrepresentation. Below I will elaborate further my reference to 'Southeast Asian area studies'. Suffice to note here that it refers to the dominant concept and institutionalised practice of academic enquiry into the region from the Cold War period. Likewise, references to 'cultural studies' primarily allude to the most influential approaches, authors and works that feature so prominently in textbooks, journals and introductory discussion of the field that they appear to have acquired a semi-canonical status. Both cultural and area studies will be analysed below as a matrix of interconnected and mutually constitutive institutions and intellectual practices of knowledge production, within specific historical settings where the politics of naming and certified authority are critical.

\section{Internationalisation of cultural studies}

Why cultural studies should be considered in a discussion of a future Southeast Asian studies has something to do with their historically situated intersections in the broader context of the de-Euro-Americanisation of academic knowledge production. There have been serious concerns about the depoliticisation of cultural studies, its submission to the corporatised university system (Rutherford, 2005) and the commercially driven international publishing industry (Striphas, 2002). Contemporary cultural studies is by no means a flawless remedy that promises some magic cure to area studies' problems. However, it is necessary not to lose sight of the strengths of earlier cultural studies as it developed a critique of its immediate contexts. ${ }^{2}$ It is equally important not to over-react to the downsides of institutionalisation of what began as a spirited anti-establishment movement.

From its inception, in varying degrees and contexts, cultural studies has aimed to make a politically conscious departure from the mainstream of academic practice. It has resisted universalist claims, and radically questioned academic disciplinary boundaries and authority. From early on, cultural studies has tried to be sensitive to and engage with specific social relations and practices within specific contexts, in appreciation of the local in the global and vice versa. Disclaimers about the limited scope of one's project are recited repeatedly. Unsurprisingly, a centrifugal tendency has marked the otherwise transnationalist practice, making it increasingly difficult to make any general statement about cultural studies, beyond brief and abstract comments.

Curiously, this centrifugal drive has found its most pronounced expressions in national or regional territories: British cultural studies, French cultural studies, American cultural studies, Japanese cultural studies, South Asian cultural studies and so on - a trend whose immanent dangers have been noted by Stratton and Ang (1996). It is curious because this process took place when the criticism of the parochialism of single country-based area studies intensified. In Asian area studies since the 1990s 'internationalisation' has meant expanding the scope of analysis for comparative purposes. The internationalisation of cultural studies implies a contraction of the claims and scope of analysis. Despite this contrast, both are a response to the dominant position of the West. In cultural studies, this 
refers specifically to the privileged positions of British and American cultural studies (see Abbas and Erni, 2005; Ang and Stratton, 1996; Chen, 1996; Shome, 2009). Such resistance is problematic, because 'the nationalist perspective turns out to be the other side of the coin of the universalist, neo-colonialist perspective which implicitly posits the British and/or American version as the original form of, and standard for, cultural studies elsewhere' (Stratton and Ang, 1996: 380). So common is the focus on the specific and particular for cultural studies that one wonders what a Southeast Asian cultural studies might look like. This question will be discussed in the next two sections, in the contexts of two related phenomena: the 'crisis' of Southeast Asian studies in North America, Western Europe and Australia; and, somewhat contradicting the first, the so-called 'rise of Asia'.

References to area studies are not uncommon in cultural studies discourses, and vice versa. Most of these references consist of terse comments in passing. One notable exception is Jackson (2003a, 2003b), whose work represents a rare extensive investigation of the links between cultural studies and Southeast Asian studies, especially Thai studies. ${ }^{3}$ Louw (2003), Burgess (2004) and Schäfer (2009) also probe deeply into the intimate intersections between the two sorts of studies. Louw is very positive about the potential contribution of cultural studies to African studies; Burgess is enthusiastic about the productive links between cultural studies and Japanese studies; while Schäfer puts forward a fascinating analysis of the long and rich history of the two sorts of studies in Japan.

Jackson's work (2003a, 2003b) is most directly related to this article, but it also departs from my current concerns in several ways. Jackson focuses on 'bad' examples of cultural studies work on Asian studies, ${ }^{4}$ with a brief concluding section on alternative scenarios. In contrast, this article is devoted to highlighting the more positive areas in the links between the two. Jackson's work refers mainly to the politics of knowledge in English-speaking scholarship and universities in the West (Jackson, 2003b: 82-4), while the following discussion focuses on the situation in Southeast Asia itself. The main thrust of Jackson's work is a critique of American-centric cultural studies (Jackson, 2003b: 62) that has allegedly contributed to the crisis of area studies (Jackson, 2003a: 14). He argues that such intervention 'can operate as a theoretical parallel to, even legitimation for, Western geopolitical hegemony' (Jackson, 2003b: 43, 81). In Jackson's analysis, area studies appears like an innocent victim of the onslaught of western-centric cultural studies in its marriage with globalisation studies. He intends to rescue the victim and correct the perpetrators. In my observation, both area studies and cultural studies have been equally fraught with western-centrism, even if we accept the notion that some level of western-centrism is inevitable in contemporary scholarship on anything, anywhere. To borrow Chakrabarty's now famous term, both the European and American intellectual traditions of cultural studies and Southeast Asian studies require 'provincialising' (Chakrabarty, 2000).

Self-criticism has developed within cultural studies for being western-centric, despite its commitment to a radical critique of western knowledge/power and to privileging the marginal, the subaltern and the West's others. Such criticism may be valid, but the source of the problem is deeply embedded in our colonial and postcolonial histories. It cannot be entirely erased, or easily corrected globally anytime soon. Non-western agencies have always been deeply complicit in reproducing the post/colonial legacy. Paradoxically, 
cultural studies in English has attracted an increasing number of scholars and activists in Southeast Asia, as in other parts of Asia. This is not a case of transplanting a cultural practice from one place to another unchanged. As illustrated in the case of Indonesia's Kunci Cultural Studies Centre, these scholars and activists discover selected elements from their own reading of cultural studies that resonate with long-standing concerns in their home environments. One can think of several contextual reasons for cultural studies' appeal to young intelligentsia in Southeast Asia. Undoubtedly these reasons vary among social groups within and across their societies. Melani Budianta (2011) provides an insightful account of her own experience in the early developments of cultural studies across Asia from her position as an Indonesian intellectual-cum-activist engaging with the new-leftist networks of Asian Regional Exchange for New Alternatives (ARENA) and Inter-Asia Cultural Studies (IACS). Below is a brief account of the specific situation in Indonesia.

Perspectives from the major and canon-like texts in cultural studies, mainly from the UK and USA, attracted urban intelligentsia in Indonesia in the 1990s for a combination of reasons. They filled a huge intellectual gap at the time, enhancing the efforts of the urban intelligentsia to respond to the socio-political and intellectual challenges of the day. That was a period of enormous contradictions: the last decade of the militarist rule of the New Order (1966-98) that had delivered sustained economic growth, inadvertently facilitating the emergence of the new rich, the new poor and, in between, a minority of restless, urban, educated, middle-class Indonesians with aspirations for some local version of a liberal lifestyle. It was these middle classes who enjoyed major representation in public debate in the rapidly growing commercial mass media. Without their public presence, the print and screen media would have been deadly dull, filled with state propaganda images and texts, making them commercially unviable. The cultural studies that came to Indonesia might be parochially Euro-American-centric. However, it did not strike them as disturbingly foreign, partly thanks to the fact that these people had endured everyday forms of repression by the postcolonial state, which in style and form were direct legacies of European colonial modernity, nurtured by American militarism during the Cold War. Cultural studies posed a radical challenge to the politics and logic of such a regime.

Local discussions of cultural studies also appealed to a small but vocal minority of left-leaning artists and so-called 'public intellectuals'. They found the post-Marxian elements politically energising precisely because Marxism had been legally banned since 1966, following the massacres of the left in 1965-6. However, the spectre of the great cultural debate since independence kept haunting public memory. It was the debate between two major ideologically opposed groups at the height of the Cold War: the Indonesian Communist Party-affiliated Lembaga Kebudayaan Rakyat (Institute of People's Culture) or LEKRA, versus the military-backed co-signatories of the universalhumanism-inclined Manifes Kebudayaan (Cultural Manifesto) (see Foulcher, 1969, $1986,1994)$. From the 1970s, under the then prevailing modernisation theory and ideology, there was no credible theory or frame of thought that seriously dealt with art practice, popular cultures, gender, racism, religion, or everyday forms of violence and resistance among ordinary citizens - all things that cultural studies practitioners are strongly interested in. Things did not improve when modernisation orthodoxy was 
confronted from the 1980s by several variants of (neo-)Marxian critique (e.g. dependency theory, world system, structuralism), notably in the respected journal Prisma.

The extended absence of a rigorous intellectual paradigm for dealing with cultural politics was odd, given the long history of political dissidence in the country by art workers. Even if we assume that LEKRA was forgotten or silenced, Indonesia in the 1970s and 1980s saw the legendary performances of poet-cum-dramatist Rendra and musician Iwan Fals, to name just a couple of the most prominent. One of the first well-documented incidents that altered this situation, and brought cultural politics into the centre of public discussion and academic theorising, was the 'contextual literature' debate that began in 1985 (see Foulcher, 1987). The influence of Raymond Williams (a founding figure of the Birmingham school of cultural studies) was pivotal in one of the two papers that sparked the debate (Heryanto, 1984). Until then, the term 'kajian budaya' ('cultural studies') had not been widely used. Three publications dedicated to cultural studies helped popularise the term in the 1990s: the journal Kalam, the monthly supplement Bentara of the largest daily Kompas, and the English magazine Latitudes. In the early 2000s, the newly born IACS project was reaching out to like-minded groups across Asia, and in Indonesia it found the Yogyakarta-based Kunci Cultural Studies Centre as a key partner. Several universities began to open degree programs in cultural studies from the late 1990s, and the country witnessed its first international cultural studies conference in 2005 in Trawas, East Java.

Many of these scholars and activists are not formally engaged in area studies, except when they are abroad. However, their work has a huge potential to support a fledgling network of regionally based area studies. Conversely, the question needs to be asked whether area studies has the potential to fill in what is lacking in cultural studies: a critical perspective on cultural politics in the region, particularly in relation to religious issues. The latter is a harder question, which this article will discuss further, but will not answer. The remaining discussion focuses on how a locally based cultural studies may inspire, if without guarantee, some form of a locally based area studies in Southeast Asia.

\section{Rising area, declining area studies}

Like 'cultural studies', 'Asia' is a widely used term among those who do not necessarily agree on what it means. Here I wish to distinguish between two sets of overlapping meanings of 'Southeast Asia' and 'Southeast Asian studies'. Borrowing Williams' ideas on dominant, residual and emergent cultures (1977: 121-7), we can recognise a set of dominant senses that constitute the region and its studies. Of late, there has also been an emergent set of conceptions of the region and its studies that remain a work-in-progress, thus precluding a strongly worded definition for the moment. Let me elaborate these two concepts.

Since the Cold War, 'Southeast Asia' as in 'Southeast Asian studies' usually refers to the ASEAN member countries, without necessarily implying the notion of a unified, integrated or clearly bounded region. ${ }^{5}$ Even after the Cold War, this concept remains dominant, as reflected in the way major institutions and publications are categorised. For the past half a century 'Southeast Asian studies' has referred primarily to the various formally institutionalised trainings and research on two or more nation-states in the region. Conceptualised as such, mainstream Southeast Asian studies carries several or all of the following features: it operates mostly in English; it has its basis in or is affiliated 
with a university; its centres of excellence are located away from the region, with the US taking a leading role; its dominant approaches derive from the contemporary social sciences and humanities; and it is oriented towards practical value to the region, and/or the foreign superpowers that sponsor these studies for their own strategic purposes. ${ }^{6}$ A range of alternative versions does exist in the US and beyond, but none of them has rivalled the configuration above, making Asian studies primarily an academic enterprise that 'developed in an economically advanced "West" as a means of understanding a troubling "other" (Reid, 1999: 142). US-led Southeast Asian studies differs markedly from the Oriental studies that flourished during Europe's colonisation of the region, with its emphasis on philology, history and anthropology (Dutton, 2002; Emmerson, 1984; McVey, 1995).

The contrast between mainstream cultural studies and Southeast Asian studies in its dominant senses should be immediately transparent. One contrast is in their object of analysis: between a set of western-based intellectual enquiries about issues close to home and those about issues away from the researchers' home environment. This appears as the reverse of the older division of labour in western academia, where 'sociology was concerned with "our own" "Western" society/ies - that is, in the epistemology of representation, cultures which are (like) "us" - and anthropology was concerned with cultures that were constituted as Other - not (like) "us" (Ang and Stratton, 1996: 23). Like many other disciplines before it, cultural studies questions empiricist or objectivist conceptions of 'culture'. Until recently, Southeast Asian studies has been strongly characterised by its objectivism and empiricism.

The contrast between cultural studies and area studies has now narrowed. Inspired by a host of newly critical perspectives in the humanities, Southeast Asian studies underwent significant changes, leading to the emergence of new ideas of what constitutes the region and its studies. The emphasis has shifted from nation-states as a unit of analysis to supra-national and sub-national networks that cut across porous national borders, those at borderlands, or those with transnational or global engagements, including the diasporas. Instead of focusing on the elite or the poor peasants, scholars have increasingly taken a serious interest in urban youth, gender and pop cultures. Instead of being conceptualised primarily in geographical or political terms, Southeast Asia has been problematised and reconceptualised as a discursive construct of space. This article is interested in exploring the potential intimacy between cultural studies and Southeast Asian area studies in the more recent and post-Cold War senses.

Cultural studies has made important, by no means exclusive, contributions to these recent shifts in Asian studies as attested in the past decade or so by the contents of Asian Studies Review, the flagship publication of the Asian Studies Association of Australia. ${ }^{7}$ The steady flow of cultural studies perspectives into Asian studies has been cause for concern among some. One expression of such concern comes from a well-respected scholar of Thai studies:

The most trenchant critiques of Southeast Asian studies ... will come from the new anthropology and from cultural studies. This is already happening, as academics with little or no Southeast Asian language training step on to the stage from what we think of as nowhere to make smart, useful remarks about what is happening in the region today. (Reynolds, 1995: 439) 
Elsewhere Reynolds adds: '[n]ew intellectual currents are also contributing to the devaluation of area studies. I am thinking here of the fashion for, among other things, postcolonial and cultural studies' (1998: 13-14). In his critique, Jackson (2003a, 2003b) presents a long list of 'bad' examples of cultural studies works on Asia that he considers seriously flawed and harmful to area studies. Jackson distinguishes between 'bad' practice of cultural studies in the wrong hands, and the potentially 'good' merits of cultural studies that remain to be developed, or 'transculturated' (Jackson, 2003a: 7). Among the more conservative and sceptical scholars of Southeast Asian studies, cultural studies appears as simply another threat to an already embattled area studies, which barely survived the earlier attacks from disciplinary-based scholars. ${ }^{8}$

The decline of Southeast Asian studies has not taken place evenly, and neither has its 'crisis' been perceived uniformly. The intellectual rigour of conferences hosted by the world's two largest networks, the US-based Association of Asian Studies (AAS) and Europe-based International Convention of Asia Scholars (ICAS), and the robustness of journals like Asian Studies Review, Critical Asian Studies, Journal of Asian Studies, Journal of Contemporary Asia, Journal of Southeast Asian Studies and Pacific Affairs to name a few (and not to mention those dedicated to specific countries or allied with specific disciplines), belie the doomsayers' arguments. Dismissing the Asian studies crisis thesis, Carol Gluck (2011) asserts that Asian studies has been considered to be in crisis from the beginning of its history, yet it has survived well into the new century.

Notwithstanding such optimism with regard to academic research in Asia studies, the overall picture is much less bright for undergraduate training in the same field. There may be no shortage of dedicated scholars in Southeast Asian studies or of high-quality works. However, with a few exceptions, these scholars are scattered in many disciplinary departments instead of being formally brought together under a single college, faculty or school specifically devoted to Southeast Asian studies, and named as such. The overall number of full-time faculty members and enrolled students in Southeast Asian studies has declined over the past two decades.

The crisis has generated a wide variety of responses. Two opposing responses are at the extreme ends of the spectrum, both propose a total break with area studies from the Cold War era. One of these, located principally in western academia, argues that area studies has no strong disciplinary rigour or theoretical innovation, and thus has no legitimacy to stand on a par with existing disciplines. Proponents of this view argue that we should return to the old academic structure of division by discipline. ${ }^{9}$ The case of the IACS project, discussed below, addresses the old question about area studies' legitimacy as a distinct intellectual exercise due to the region's alleged lack of internal coherence as an object of analysis. One wonders if there exists a single discipline in the social and human sciences whose object of analysis is a fully integrated entity; definitely not humans, nor societies, histories or cultures.

At the other end of the scale, in response to the once hegemonic US-led area studies now in crisis, some have attempted to revive the old aspiration for some sort of indigenous social sciences (see Alatas, 2000; Luna, 1999). One sub-stream within this group seeks inspiration from Islamic traditions (Ragab, 1998). Like most crises, the current crisis of area studies offers a window of opportunity for exploring new territory and potentials for innovation and change. Instead of quickly taking the nostalgic turn to the 
old established order, it would be worth considering two other sets of response for their innovative experiments and forward-looking orientation.

The third type of response to the crisis of area studies emerged in the late 1990s in a series of attempts to build a locally based area studies in Southeast Asia. These were collective efforts on the part of local scholars with support from external funding agencies (for details see Budianta, 2011; Goh, 2011; Heryanto, 2002). Most prominent among them are the Southeast Asian Studies Regional Exchange Program (SEASREP, founded 1995); Asian Studies in Asia Fellowship Program (AsiA FP, founded 1999) before transforming into the Asian Scholarship Foundation (ASF) from 2002; and the Asian Public Intellectuals (API) fellowships (founded 2000). Their genealogical links with Southeast Asian studies from the second half of the previous century is acknowledged, but their desire to address local needs, plus the practical requirements to operate locally, meant that these projects would not and could not simply mimic or resurrect their predecessors. Cultural studies has not featured prominently in any of these endeavours, presumably not because it has been rejected but because of a lack of interest in or familiarity with cultural studies among those who participated in these projects. The initial outcomes of these various initiatives for the first decade were encouraging, but before long some found themselves in an uphill battle over diminishing resources, while their long-term and often ambitious aims remain some distance away.

Groups of scholars, artists, activists and professionals in Southeast Asia have developed collaborative projects of various scales in old and new formats on a regular basis (Budianta, 2011; Heryanto and Mandal, 2003). They actively participate in the production of knowledge about the region, both scholarly and non-scholarly, expanding and complicating the senses of their local identity and regional solidarity. Their work does not usually carry the label 'area studies', but it would be unwise to underestimate the potential value of their work to contemporary studies of the region. As younger Asians rediscovered each other, for the first time in almost a hundred years 'East versus West' has ceased to be the salient discursive frame or trope in public debate. This leads us to the fourth response to the current state of area studies for consideration, namely the IACS project.

\section{A case of intimacy}

In May 2010 the journal Inter-Asia Cultural Studies launched a special issue commemorating its 10th anniversary. For Meaghan Morris (2010) it is not the journal's achievements as a peer-reviewed publication that impress her most. Rather, she describes in detail the broad scope and multiple fronts and levels that the movement has covered over the decade, involving many people and institutions across Asia, compelling anyone seriously interested in cultural studies, Asian studies and the intimacies between them to take a closer look (see also Chen, 2010b). The project has not been free of criticism: for publishing in English; for becoming 'just another cultural studies' (Willemen, 2010: 221); for being incorporated into the logic of the mainstream publication industry; and for imbalance in engaging with the region and transnational allies (Barlow, 2010). My own regret is the serious under-representation of self-reflexive analyses on the Islamic societies in the region. On balance, however, the project's achievements well outweigh its 
shortcomings, thanks to the solid dedication of its key co-founders Chen Kuan-Hsing and Chua Beng-Huat.

The journal is a part of a larger project, or 'movement', as its co-founders call it. It is not specifically designated as an area studies journal. For the purpose of this article, however, this feature is a blessing, not a liability. North and East Asia are by far overrepresented in terms of the themes discussed and the authors' place of residence. Notwithstanding this imbalance, the project offers one promising model for a post-Cold War area studies. Despite being under-represented, Southeast Asia has played an important role in the broader intra-Asia dialogue. More importantly, by dissolving artificial regional boundaries, by engaging cross- and trans-nationally with the multiplicity of Asia(n)(ess) (thus 'intra-Asia'), and not falling into another superficially defined entity called 'Asia', the project addresses effectively some of the old and serious problems of area studies.

Chen's recent book Asia as Method (2010a) gives serious consideration to the problematic status of area studies in relation to the future of cultural studies in the region. Most of his arguments deserve support. However, one point he notes:

Interestingly, with the rise of Asia, we have suddenly found that we have been doing Asian studies in our own way, without using that name. The absence of the name, in fact, indicates our own lack of consciousness about Asia. If Asian studies is broadly defined as the field whose object of analysis is located in Asia, we will find that most of the research carried out in different parts of the region is in fact Asian studies. If one accepts this observation, it is clear that the largest number of practitioners of Asian studies are indeed in Asia, rather than outside the region ... (Chen, 2010a: 3)

I am unsure who the collective 'we' refers to, or why the 'rise of Asia' should necessarily entail a new revelation about Asians doing Asian studies in Asia. Earlier in this article I introduced a concept of 'Southeast Asian studies' as a specifically and historically bound social institution (the Cold War, US sponsorship, the use of English, modernisation theory and a utilitarian orientation). Studying and knowing something from/of Asia does not automatically render the exercise 'Asian studies' and the person an 'Asianist'. As Reid puts it: "[m]ost of our Asian colleagues ... are only "Asianists" when they are outside Asia, but discipline-based social scientists at home' (1999: 142). Actually, the same applies to those from other parts of the world with expertise on aspects of their home countries, but this is not my current concern.

What constitutes an 'area studies' (or other certified knowledge and expertise for that matter) is its official status, or its recognised institutional base in the production and distribution of knowledge. Justifiably or not, these seemingly artificial features serve as the basis for the claims for recognition of some authorised field of expertise (instead of others), generating the authority to operate in public space and services otherwise restricted - like teaching or applying for grants - and the reward systems for those contributing to the reproduction of this structured institution. The current crisis of Southeast Asian studies in North America, West Europe or Australia should be understood precisely as a crisis of its formal status, institutional resources and certified existence, regardless of the number of scholars who engage individually in the studies of the region at their discretion. 
For the same reasons, the politics of naming the project 'Inter-Asia Cultural Studies: Movements' is critical to its force as an ingenious statement, social movement and political intervention in the status quo in both area studies and cultural studies. Many of the original research articles in the Inter-Asia Cultural Studies journal could have easily appeared in various academic journals that do not carry 'Asia' or 'area studies' or 'cultural studies' in their names. By privileging the terms 'Asia' and 'cultural studies', the IACS project articulates, and thus gives a legitimate presence to local practice and networks in a way that significantly departs from the old familiar traditions in academic disciplines, as well as area studies. '[W]ithout using that name' (Chen, 2010a: 3), the various attempts to build Asian studies in Asia would have been silenced or marginalised in the public consciousness. The postcolonial emphasis in the name exempts us from the common preoccupation with nationalistic-informed acts of nationalising or inter-nationalising cultural studies as taking place elsewhere. ${ }^{10}$

\section{Concluding note}

There has been no crisis of Southeast Asian studies in Southeast Asia, as the field was never a preoccupation within the region. One can expect a sharp increase of local interest in knowledge about new transnational institutions based in the region, about the flows of peoples, religious solidarity and militants, and pop culture industry. New demands for understanding the region have been prompted by the increased pressures on various fronts, ranging from health and environment, to economic cooperation and competition, border security, tourism, education or migrant labour. By no means is the future all rosy as implied by the phrase 'the rise of Asia'.

In most parts of Southeast Asia, the forces which cultural studies in the advanced capitalist societies resists are not well established. Weak separation between officially certified and non-certified expertise, weak disciplinary divisions in the academy (see Hadiz and Dhakidae, 2005), overtly state-sponsored violence in everyday life, the absence of an orthodox liberal humanism (Chua, 2010) and a fairly strong history of political activism (Heryanto and Mandal, 2003) promise some advantages with no guarantee, while also posing other kinds of challenges in the formative years of a locally based cultural studies. If a locally based intimacy of cultural/area studies does develop and sustain itself in Southeast Asia, it remains to be seen whether it will make a distinct contribution to other area studies and cultural studies. One potential contribution of interest pertains to the cultural politics of human and capital-intensive investment in religious piety in the context of a secular capitalist society. In the past decade or so Indonesia (the world's largest Muslim nation) has seen Islamisation taking place, unprecedented in scale and speed. However, Islam is never one thing to all Muslims. To complicate matters, even non-believers or less religiously minded groups and individuals cannot resist the temptation to jump on the bandwagon and exploit Islamisation, pushing it to dangerous extremes. This historic change is far too important and complex to be left exclusively to analysts in the old social sciences and humanities. Serious investigation in cultural studies on this area has barely begun (see Weintraub, 2011).

In contemporary Indonesia, as elsewhere, capitalist greed for wealth and the commitment to religious piety can escalate hand in hand for various - occasionally contradictory 
- reasons. Religion serve as a sigh of relief for the disadvantaged with no representation or alternative recourse. For the urban and more advantaged groups of critics of the status quo, religion can serve as a convenient rallying point of dissent when all other legitimate venues of formal politics (parliament, the justice system, the media) have been curtailed, as seen in the decades immediately before and after the fall of the New Order rule in Indonesia (Brenner, 1996; Heryanto, 2008; Murray, 1991). For those in power, religious piety can help restore their self-esteem or ease a sense of guilt (if they have any) in their private life, surrounded by gross poverty, rampant corruption and unabated state-sponsored violence; or to neutralise the public perception of their questionable greed for power and wealth. Whether or not those actions meet with any success is a different matter.

If a post-Cold War study of the region does develop and thrive locally, it would possibly not call itself 'area studies' or speak of the region as 'Southeast Asia'. From whose perspective and orientation would south and east appear, anyway? However, it would still require new and strategically chosen names, labels, discourse and organisational structures. ${ }^{11}$ The IACS project is just one, and hopefully not the only or last, innovative and robust format for Southeast Asians to collaborate intellectually in knowledge production and dissemination about themselves, within and beyond formal academic institutions, within and beyond Asia. The size and overwhelming diversity and complexity of this vibrant region, and its messy relations with the rest of the world, dwarf even the best possible achievements of an extremely impressive project such as the IACS.

\section{Funding}

This article is part of a larger work-in-progress, supported by ANU's College of Asia and the Pacific and the Australian Research Council.

\section{Notes}

1. Participants of three separate meetings helped me rethink many of the issues presented here: two workshops on 'Intersections of Area, Cultural and Media Studies' in Canberra (February 2010 and April 2011); and the AAS panel 'Intimacies of Cultural/Area Studies', Hawaii (April 2011).

2. The contribution of Birmingham cultural studies of the 1970s and 1980s is duly acknowledged, leaving aside the contention of whether it represents 'British cultural studies' and the 'origin' of cultural studies worldwide. I follow the general consensus that there is no single 'cultural studies' across the globe, or 'cultural studies per se' (Stratton and Ang, 1996). See Grossberg's (2010) reflections on related issues.

3. Although presented as two articles in one journal issue, they read as one long piece of 88 pages in print in two parts. See critical comments on this work by Curraming (2006), to which Jackson (2006) responds.

4. Elsewhere I have discussed my mixed feelings about the contribution of the various post-isms to Southeast Asian studies (Heryanto, 1995: 41, 2002: 19-20).

5. Conscious of their specialisation, some scholars prefer a country-based alternative (e.g. Indonesian studies) to the broader designation 'Southeast Asian studies'. Such acts of downscaling, however, do little to solve the problem of over-representation. For example, 'Indonesian studies' disproportionately consists of studies of the history, space and people in the island of Java, particularly the nation's capital city of Jakarta.

6. Most academic work in other disciplines may also demonstrate similar utilitarian claims. However, these claims may differ significantly from those commonly found in area studies in 
the degree of their frequency, explicitness or proportion. See Mitchell (2003) for a discussion of the utilitarian orientation of the social sciences and the humanities in the US. Harootunian (2003) launches one of the strongest criticisms of US-based area studies as serving the interests of its major sponsors: government offices and corporations.

7. In the absence of general consensus as to what is, is not, or is partially 'cultural studies', this statement is open to debate. Conversations with former editors of the journal confirm my casual observation that articles with partial or strong cultural studies perspectives are well represented in this Australian-based journal in the 2000s.

8. I discuss these concerns further in Heryanto (2002: 18-19). A longer history of tension between academic disciplines and area studies, as well as between disciplines and cultural studies, lies beyond the scope of the current discussion. Timothy Mitchell argues that the social sciences are in fact in serious crisis, that is partly responsible for the crisis of area studies (2003: 161).

9. Such a view was explicitly expressed in at least two separate meetings I convened: the 'Intersections of Area, Cultural and Media Studies' workshop (Canberra, 25 February 2010) and 'Intimacies of Cultural/Area Studies' panel at the Association of Asian Studies conference (Honolulu, 31 March 2011)

10. See Ang and Stratton (1996) on the distinction and tension between national versus nationalistic features pertaining to the internationalisation of cultural studies.

11. Sakai (2010: 273) proposes substituting 'transnational studies' for 'area studies'.

\section{References}

Abbas A and Erni J (eds) (2005) Internationalizing Cultural Studies. Malden, MA: Blackwell.

Alatas S (2000) Intellectual imperialism: definition, traits, and problems. Southeast Asian Journal of Social Science 28(1): 23-45.

Ang I and Stratton J (1996) Asianing Australia: notes toward a critical transnationalism in cultural studies. Cultural Studies 10(1): 16-36.

Barlow T (2010) Region, cultural studies, friends. Inter-Asia Cultural Studies 11(2): 236-40.

Brenner S (1996) Reconstructing self and society: Javanese Muslim women and 'the veil'. American Ethnologist 23(4): 673-697.

Budianta M (2011) Made in Asia? Doing cultural studies in the region. Paper for panel 'Intimacies of Cultural/Area Studies', Association for Asian Studies (AAS) Annual Meeting, Honolulu, 31 March-3 April.

Burgess C (2004) The Asian studies 'crisis': putting cultural studies into Asian studies and Asia into cultural studies. International Journal of Asian Studies 1(1): 121-136.

Chakrabarty D (2000) Provincializing Europe: Postcolonial Thought and Historical Difference. Princeton, NJ: Princeton University Press.

Chen K (1996) Not yet the postcolonial era. Cultural Studies 10(1): 37-70.

Chen K (2010a) Asia as Method; Toward Deimperialism. Durham, NC: Duke University Press.

Chen K (2010b) Living with tensions: notes on the inter-Asia movement. Inter-Asia Cultural Studies 11(2): 311-318.

Chua B (2010) Disrupting hegemonic liberalism in East Asia. boundary 2 37(2): 199-216.

Curraming R (2006) Towards a poststructuralist Southeast Asian studies? Sojourn 21(1): 90-112.

Dutton M (2002) Lead us not into translation: notes toward a theoretical foundation for Asian studies. Nepantla 3(3): 495-537.

Emmerson D (1984) 'Southeast Asia': what's in a name? Journal of Southeast Asian Studies 15(1): 1-21.

Foulcher K (1969) A survey of events surrounding Manikebu. Bijdragen tot de Taal-, Land-en Volkenkunde 125(4): 429-465. 
Foulcher K (1986) Social Commitment in Literature and the Arts: The Indonesian 'Institute of People's Culture', 1950-1965. Clayton, Vic.: Centre of Southeast Asian Studies, Monash University.

Foulcher K (1987) Sastra kontekstual: recent developments in Indonesian literary politics. Review of Indonesian and Malayan Affairs 21(1): 6-28.

Foulcher K (1994) 'The Manifesto Is Not Dead': Indonesian Literary Politics Thirty Years On. Clayton, Vic.: Centre of Southeast Asian Studies, Monash University.

Gluck C (2011) Looking back and looking forward: AAS and Asian studies, 1960-2010. Paper for Association for Asian Studies (AAS) Annual Meeting, Honolulu, 31 March-3 April.

Goh B (ed.) (2011) Decentering and Diversifying Southeast Asian Studies: Perspectives from the Region. Singapore: Institute of Southeast Asian Studies.

Grossberg L (2010) Cultural Studies in the Future Tense. Durham, NC: Duke University Press.

Hadiz V and Dhakidae D (eds) (2005) Social Science and Power in Indonesia. Jakarta: Equinox.

Harootunian H (2003) Postcoloniality's unconscious/area studies' desire. In: Miyoshi M and Harootunian H (eds) Learning Places: The Afterlives of Area Studies. Durham, NC: Duke University Press, pp. 150-174.

Heryanto A (1984) Sastra 'dan' Politik (Literature and politics). Review of Indonesian and Malayan Affairs 18(summer): 6-43.

Heryanto A (1995) What does postmodernism do in contemporary Indonesia? Sojourn 10(1): 33-44.

Heryanto A (2000) Asians studying other Asians in Asia: what difference does it make? SEAS Bulletin 2(Oct.-Nov.): 4-7, 26-27.

Heryanto A (2002) Can there be Southeast Asians in Southeast Asian studies? Moussons 5: 3-30.

Heryanto A (2008) Pop culture and competing identities. In: Heryanto A (ed.) Popular Culture in Indonesia: Fluid Identities in Post-authoritarian Politics. London: Routledge, pp. 1-36.

Heryanto A and Mandal S (eds) (2003) Challenging Authoritarianism in Southeast Asia: Comparing Indonesia and Malaysia. London: RoutledgeCurzon.

Jackson P (2003a) Space, theory, and hegemony: the dual crises of Asian area studies and cultural studies. Sojourn 18(1): 1-41.

Jackson P (2003b) Mapping poststructuralism's borders: the case for poststructuralist area studies. Sojourn 18(1): 42-88.

Jackson P (2006) Why I'm a Foucauldian. Sojourn 21(1): 113-123.

Louw E (2003) Does cultural studies have anything to offer African studies? Paper presented at the African Studies Association of Australasia and the Pacific Conference, Adelaide, 1-3 October.

Luna E (1999) Rethinking community development in the Philippines: 'indigenizing' and regaining grounds. In: Miralao V (ed.) The History and Development of Social Science Disciplines in the Philippines. Quezon City: Philippine Social Science Center, pp. 315-343.

McVey R (1995) Change and continuity in Southeast Asian studies. Journal of Southeast Asian Studies 26(1): 1-9.

Mitchell T (2003) Deterritorialization and the crisis of social science. In: Mirsepassi A, Basu A and Weaver F (eds) Localizing Knowledge in a Globalizing World. Syracuse, NY: Syracuse University Press, pp. 148-170.

Morris M (2010) Inter-Asian banality and education. Inter-Asia Cultural Studies 11(2): 157-164.

Murray A (1991) Kampung culture and radical chic in Jakarta. Review of Indonesian and Malayan Affairs 25(winter): 1-16.

Ragab I (1998) On the methodology of the Islamization of the social sciences. Available at: http:// msanews.mynet.net/Scholars/Ragab/ragab.html (accessed 20 September 2001).

Reid A (1999) Studying 'Asia' in Asia. Asian Studies Review 23(2): 141-151.

Reynolds C (1995) A new look at old Southeast Asia. Journal of Asian Studies 54(2): 419-446.

Reynolds C (1998) Self-cultivation and self-determination in postcolonial Southeast Asia. In: Southeast Asian Studies: Reorientations. Ithaca, NY: Cornell Southeast Asia Program, pp. 7-35. 
Rutherford J (2005) Cultural studies in the corporate university. Cultural Studies 19(3): 297-317. Sakai N (2010) From area studies toward transnational studies. Inter-Asia Cultural Studies 11(2): $265-274$.

Schäfer F (2009) The re-articulation of cultural studies in Japan and its consequences for Japanese studies. International Journal of Cultural Studies 12(1): 23-41.

Shome R (2009) Post-colonial reflections on the 'internationalization' of cultural studies. Cultural Studies 23(5): 694-719.

Stratton J and Ang I (1996) On the impossibility of a global cultural studies: 'British' cultural studies in an 'international” frame'. In: Morley D and Chen K (eds) Stuart Hall; Critical Dialogues in Cultural Studies. London: Routledge, pp. 360-392.

Striphas T (2002) Banality, book publishing and the everyday life of cultural studies. International Journal of Cultural Studies 5(4): 438-460.

Weintraub A (ed.) (2011) Islam and Popular Culture in Indonesia and Malaysia. London: Routledge. Willemen P (2010) A critical comment on the IACS Journal. Inter-Asia Cultural Studies 11(2): 221-223.

Williams R (1977) Marxism and Literature. Oxford: Oxford University Press.

\section{Author biography}

Ariel Heryanto is Associate Professor at the School of Culture, History and Language, The Australian National University. 